\title{
Construção e reconstrução multicultural de identidades docentes: pensando na formação continuada de coordenadores pedagógicos*
}

Ana Canen

Angela Rocha dos Santos

\section{Resumo}

Trata de uma pesquisa-ação que envolveu a formação continuada de coordenadores pedagógicos do Estado do Rio de Janeiro em 2005, desenvolvida pela Universidade Federal do Rio de Janeiro e a Secretaria de Estado de Educação do Rio de Janeiro. Focaliza, a partir de uma perspectiva multicultural, as formas pelas quais a construção e reconstrução identitária dos sujeitos envolvidos na referida ação foi buscada na proposta e nos materiais elaborados. Apresenta as construções discursivas sobre temas didático-pedagógico-curriculares, trabalhados na perspectiva multicultural, no âmbito dos módulos produzidos para o curso, visando contribuir para reflexões sobre possíveis traduções do multiculturalismo para propostas didáticas e curriculares concretas em ações de formação inicial e continuada de docentes.

Palavras-chave: formação continuada; identidade docente; multiculturalismo; pesquisa-ação.

\section{Abstract}

Multicultural construction and reconstruction of teachers' identity: thinking on a continuing education of pedagogical coordinators

The present article is an action research that involved continuing education of pedagogical coordinators of the state of Rio de Janeiro, developed by the Federal University of Rio de Janeiro and the Rio de Janeiro Secretariat of Education. It focuses the ways by which construction and reconstruction of pedagogical coordinators' permeated the discourses within the referred program and its related materials, based on a multicultural perspective. It presents the discursive constructions on curricular, pedagogical and didactic themes of the program within the modules produced for the course, aiming at contributing for reflections about possible translations of multiculturalism in concrete didactic and curricular proposals within both initial and continuing teacher education.

Keywords: continuing education; teacher identities; multiculturalism action research.

\footnotetext{
Uma versão preliminar deste artigo foi apresentada no XIII Endipe, maio de 2006, realizado na Universidade Federal de Pernambuco (UFPE), Recife, PE.
} 


\section{Introdução}

Pensar em sinergias entre instituições de formação de professores e a escola constitui-se um dos meios mais promissores para promover o fortalecimento da educação básica e, conseqüentemente, contribuir para a solução dos grandes problemas sociais existentes no nosso país. Particularmente, esse efeito transformador pode se concretizar e se multiplicar por intermédio de ações desenvolvidas mediante parcerias de universidades públicas com secretarias de Estado de educação para a formação continuada de professores e gestores da rede. Em um contexto de discursos políticos que urgem a universidade a desenvolver projetos extensionistas de impacto, ações na formação de professores podem redundar na melhoria do ensino, bem como na reflexão sobre formas de promoção do sucesso escolar e sobre meios de minimizar a exclusão e a marginalização que atingem camadas sociais e econômicas desfavorecidas de nossa população. Assim, tais ações revestem-se de papel político e social estratégico.

Em uma perspectiva multicultural pós-colonial (Assis, Canen, 2004; Hall, 2003) valorizadora da diversidade cultural e voltada aos processos discursivos de formação das identidades plurais docentes e discentes no contexto educacional, argumentamos, no presente artigo, que tais espaços de parceria no contexto da formação continuada podem, em uma dimensão adicional à perspectiva extensionista, representar um campo fértil de pesquisa, nos moldes da pesquisa-ação (André, 1995; Barbier, 2002).

De fato, conforme Barbier (2002), a metodologia da pesquisa-ação obriga o pesquisador a agir e, assim, a perceber-se como implicado pela estrutura social na qual está inserido, como, também, a compreender as implicações dos outros sujeitos por meio de seu olhar e de sua ação singular no mundo. A partir de Carr e Kemmis, Barbier (2002) aponta que a pesquisa-ação permite aos docentes participarem diretamente da produção do conhecimento sobre as questões e os problemas que lhes concernem, sendo que tal metodologia atende a cinco exigências:

a) rejeita noções positivistas de racionalidade, objetividade e verdade; b) emprega categorias interpretativas dos docentes e demais participantes do processo educativo;

c) promove o questionamento crítico sobre idéias e interpretações, buscando seus vieses ideológicos;

d) empenha-se em verificar o que bloqueia a mudança racional e propõe interpretações teóricas que ajudem a superar tais bloqueios;

e) funda-se na premissa de que se trata de um conhecimento prático, uma "ciência da práxis exercida pelos técnicos no âmago de seu local de investimento" (Barbier, 2002, p. 59).

Assim, o objeto da pesquisa é "a elaboração da dialética da ação, num processo pessoal e único de reconstrução racional pelo ator social".

A partir de tais reflexões, a ação em foco constituiu-se uma pesquisa-ação cuja pertinência e justificativa deu-se em uma dupla perspectiva: de um lado, permitiu que docentes da Universidade pudessem articular a perspectiva multicultural à prática da elaboração do material didático e à reflexão crítica sobre ele, relacionando teoria e prática e produzindo conhecimento na dialética entre ambas, na formação continuada de coordenadores pedagógicos; por outro lado, a pesquisa-ação foi o motor que engendrou a construção discursiva do material mencionado (como será visto a seguir), isto porque essa construção visava tornar os próprios coordenadores pedagógicos pesquisadores em ação, isto é, atores sociais que não fossem limitados a meros receptores de informações, mas que, ao contrário, as problematizassem, dialogando com o material e interagindo por meio do relato de suas próprias ações e práticas.

Dessa forma, como comentado anteriormente, a pesquisa-ação representou o caminho trilhado na realização da formação continuada em foco, refletindo-se nos discursos contidos nos módulos produzidos. Tal perspectiva possibilitou reflexões sobre a tradução do multiculturalismo para o currículo em ação e para práticas didáticas e pedagógico-curriculares na escola, questionando seus sentidos, pensando em suas traduções no contexto concreto das escolas do sistema público de ensino, bem como articulando as reflexões teóricas 
multiculturais com a análise de seus limites, possibilidades e tensões no espaço de ensino público. Nessa perspectiva, ações de formação continuada são vistas como espaços de construção e reconstrução identitária dos atores envolvidos, tanto os da escola como os da universidade e da secretaria de educação, na parceria em questão.

O argumento que desenvolvemos é o de que o multiculturalismo, no âmbito de ações de formação continuada, pode abarcar não apenas formas de trabalhar a diversidade cultural e perspectivas anti-racistas e antidiscriminatórias nos conteúdos ministrados, como também pode impregnar discursos sobre temas mais convencionais da didática e do campo curricular. Na perspectiva da pesquisaação desenvolvida, isso significou irmos além das teorizações que normalmente dominam as discussões multiculturais, contribuindo para a construção e reconstrução das identidades envolvidas, no âmbito da formação continuada de docentes e gestores.

É nessa perspectiva que se colocou o presente estudo, que, como discutimos anteriormente, trata de uma pesquisaação que envolveu a formação continuada de coordenadores pedagógicos do Estado do Rio de Janeiro. Essa ação, denominada de Formação Continuada de Coordenadores Pedagógicos, foi coordenada pelas autoras do presente artigo, em 2005, no âmbito do Programa Sucesso Escolar, desenvolvido mediante parceria da Universidade Federal do Rio de Janeiro com a Secretaria de Estado de Educação do Rio de Janeiro (SEE-RJ). Nos limites do artigo, não serão analisados os discursos orais em sala ou as atividades desenvolvidas pelos cursistas, mas tão-somente as construções discursivas sobre temas didático-pedagógico-curriculares trabalhados na perspectiva multicultural abraçada, nos módulos produzidos para o curso. Estruturamos o artigo de forma que, primeiramente, discutamos concepções alargadas do multiculturalismo, para, em seguida, nos debruçarmos sobre os discursos didático-pedagógico-curriculares construídos na pesquisa-ação, de modo a contribuir para reflexões sobre possíveis traduções do multiculturalismo para propostas didáticas e curriculares concretas, no âmbito de ações de formação inicial e continuada de docentes.

\section{Multiculturalismo, identidades e propostas didático-curriculares: articulações na formação continuada de professores e gestores educacionais}

Refletir sobre a formação de professores e gestores escolares em meio a um mundo globalizado, tecnologizado, mas ao mesmo tempo plural, constituído na diversidade de raças, etnias, gêneros, opções sexuais, religiões, linguagens e outros marcadores identitários, é o grande desafio da educação nesse novo milênio.

Como vertente dos estudos culturais, o multiculturalismo, no campo da educação, apropria-se da centralidade da cultura e da desconstrução dos discursos educacionais de modo a produzir, de forma pró-ativa, respostas concretas à diversidade cultural. Assim, o multiculturalismo, segundo Kincheloe e Steinberg (1997), pode ser definido como um conjunto de respostas à diversidade cultural. Tais respostas visam ao trabalho com as identidades dos sujeitos - sejam docentes, discentes ou outras -, percebidas como necessariamente plurais, formadas de marcadores como raça, etnia, gênero, classe social, religião, opção sexual e outros. É importante notar que as identidades, no multiculturalismo, são sempre percebidas como provisórias, em processo de construção e reconstrução constantes. Nesses processos, a educação multicultural ocupa papel central, fomentando a apreciação da diversidade e o desafio a preconceitos. Além dos autores citados anteriormente, outros, como Gomes e Silva (2002) e Candau et al. (1995), por exemplo, têm discutido conceitos e experiências de valorização da diversidade cultural no cotidiano educacional.

Em outras palavras, além das análises discursivas e dos descentramentos defendidos pelos estudos culturais, o multiculturalismo possui, em seu horizonte, a premissa básica de que outros discursos alternativos devem ser construídos, voltados à valorização da diversidade cultural e ao desafio a preconceitos. E é justamente sobre esses discursos alternativos, sobre essas possibilidades de respostas ativas à pluralidade cultural, que se voltam suas atenções.

Mas que tipos de respostas seriam estas? Como ir além das identidades 
individuais e incorporar a identidade da escola como componente no pensamento multicultural? Como traduzir as tensões entre identidades individuais, identidades coletivas e a identidade da escola? Como compreender a escola como organização multicultural (Canen, Canen, 2005), marcada por relações internas plurais e, ao mesmo tempo, inserida no bojo de projetos de educação, no caso, de caráter estadual? Essas questões são centrais ao se pensar em ações de formação continuada de professores e gestores educacionais, no âmbito de parcerias de universidades públicas com Secretarias de Estado de Educação.

Nesse sentido, argumentamos que uma visão alargada do multiculturalismo implica que a relevância multicultural de tais ações se dá em uma tripla perspectiva. A primeira delas é a de que essas representam espaços possíveis de discussão de temas educacionais à luz do olhar multicultural. Isso significa articular tais temas à pluralidade cultural, a perspectivas de valorização do diverso e de questionamento das construções das diferenças e dos preconceitos. Buscam-se, assim, formas pelas quais tais questões podem ser trabalhadas no currículo, nas práticas pedagógico-avaliativas e nas metodologias didáticas. Nesse nível de discussão, pensar sobre os diferentes sentidos do multiculturalismo e suas implicações em conteúdos e atividades desenvolvidas na escola é relevante, isso porque docentes e formadores de docentes devem refletir em que medida se deseja permanecer no nível do multiculturalismo liberal, folclórico, de valorização da diversidade cultural em termos de ritos, costumes, festas e outros marcadores das identidades, ou se deseja ir além e trabalhar com a origem histórica e com as manifestações de preconceitos e desigualdades, em perspectivas mais críticas e pós-coloniais do multiculturalismo, de modo a desafiá-los (Assis, Canen, 2004; Canen, Oliveira, 2002; Hall, 2003).

A segunda vertente é a de que o olhar multicultural sobre a formação continuada, fruto de parceria de universidade e governo, trabalha possíveis tensões entre projetos políticos que propõem diretrizes curriculares e avaliativas centrais e a diversidade cultural das escolas, identidades institucionais por excelência. Isso significa perceber que as próprias escolas podem ser consideradas organizações multiculturais (Canen, Canen,
2005), formadas na confluência de identidades individuais plurais e na construção de identidades institucionais singulares. Nesse sentido, trata-se de pensar em formas pelas quais a articulação entre a diversidade cultural de identidades individuais, coletivas e institucionais pode ser buscada, sem que se caia em um relativismo total em termos de formação continuada e, ao mesmo tempo, sem que se busquem formulações centralizadoras que abafem a pluralidade dessas identidades.

A terceira perspectiva é a de se levar em conta a pluralidade dos sujeitos envolvidos na formação continuada propriamente dita, com suas singularidades e suas especificidades. Assim, busca-se romper com paradigmas de formação continuada que homogeneízam suas identidades, reduzindo-as à passividade, à condição de objetos das ações em vez de ativos sujeitos que delas participam e que atuam como peças centrais em processos de construção e reconstrução de identidades docentes, discentes e institucionais.

Essa tripla perspectiva amplia o olhar multicultural sobre a construção e reconstrução das identidades docentes, discentes e de gestores envolvidos na formação continuada, bem como sobre a construção e reconstrução da identidade da escola como organização multicultural inserida em sistemas públicos de ensino. Tal olhar traz novo fôlego às discussões sobre didática, práticas pedagógicas e outros temas centrais à formação inicial e continuada de professores e gestores educacionais. Discutiremos as formas pelas quais tal perspectiva multicultural impregnou nossa ação de formação continuada de coordenadores pedagógicos, conforme explicitada acima, focalizando, nos limites do presente artigo, as opções de tradução do multiculturalismo na construção dos discursos contidos nos módulos produzidos para o referido curso.

\section{Traduzindo o multiculturalismo nos discursos didáticos e curriculares: articulacões na formação continuada de coordenadores pedagógicos}

Como trabalhar a tripla perspectiva do multiculturalismo, nos módulos sobre 
temas didático-curriculares e pedagógicos selecionados para a formação continuada de coordenadores pedagógicos? Conforme sugerimos nas seções anteriores, uma primeira e mais conhecida faceta do multiculturalismo é o trabalho para a valorização da diversidade cultural, para o desafio a preconceitos e, na perpectiva pós-colonial, para a superação de binarismos e congelamentos identitários (Assis, Canen, 2004; Canen, Oliveira, 2002; Hall, 2003). Parte-se da idéia de que tal perspectiva promove a construção e reconstrução das identidades docentes e discentes em uma perspectiva desafiadora de pretensas idéias de universalismo e de homogeneização curricular. Nesse sentido, a pesquisa-ação buscou interferir multiculturalmente, nessa primeira abordagem, na construção discursiva dos temas propostos para a formação continuada em questão, de modo a desafiar discursos congeladores de identidades e superar noções meramente técnicas de currículo, avaliação e projeto político-pedagógico - temas centrais, entre outros, trabalhados no referido curso.

Alguns exemplos ilustram a forma pela qual essa perspectiva foi construída em nossos discursos:

Conforme discutimos no módulo 8, a perspectiva multicultural preocupa-se em indagar em que medida os currículos estão trabalhando a favor da valorização da pluralidade cultural e desafio a preconceitos, em suas formulações. O currículo, segundo esta visão, deveria trabalhar em prol da formação das identidades abertas à pluralidade cultural, desafiadoras de preconceitos, em uma perspectiva de educação para a cidadania, para a paz, para a ética nas relações interpessoais, para a crítica às desigualdades sociais e culturais. Neste tópico, buscaremos identificar, em cada área do conhecimento, elementos que se configurem como desdobramentos da perspectiva anteriormente mencionada, no que diz respeito ao desenvolvimento curricular [...]. Você pôde verificar intenções multiculturais e interdisciplinares no documento [de Reorientação Curricular] (Lavinas Pereira, 2005, p.18 e 24).

Excluir significa afastar, abandonar, despojar, discriminar, negar direitos, silenciar vozes, condenar ao insucesso alguns indivíduos apenas por serem diferentes daquilo que prejulgamos ser o "ideal", o "correto", o "perfeito", o "adequado", o "normal". [...] As noções de "normalidade" e de "diferença" são o resultado de relações sociais e de produções discursivas. Elas configuram-se como criações que envolvem relações de poder que buscam classificar, assegurar e marcar posições de sujeito na sociedade, dividindo o mundo entre "nós" e "eles", entre o "normal" e o "anormal” [...] (Xavier, 2005, p. 18).

Em uma segunda perspectiva, as tensões entre universalismo e particularismo, entre a existência de critérios ditos "universais”, mas que eram por nós encarados como historicamente construídos, e aqueles locais, focalizados, ressignificados pelos grupos, foram evidenciadas nos materiais. Por exemplo, ao falarmos sobre avaliação da aprendizagem, em uma perspectiva histórica, algumas sentenças demonstram a preocupação multicultural em termos do trabalho com as tensões entre a valorização da diversidade cultural dos sujeitos e a necessidade de trabalho com critérios que, ainda que construídos, possam balizar o julgamento de valor implícito em qualquer processo de avaliação (Canen, 2004; Canen, Oliveira, 2000). Também, em uma perspectiva multicultural, desconfiamos de discursos preconceituosos contra determinados tipos de avaliação, defendendo uma articulação entre as diversas modalidades, a favor do sucesso escolar, da valorização da diversidade cultural e da inclusão. Essas idéias aparecem, por exemplo, nos extratos abaixo:

[...] o conceito de avaliação não pode ser pensado de forma separada de uma visão de educação. No caso de uma perspectiva que valoriza a diversidade cultural dos alunos e das instituições de ensino, torna-se urgente um repensar sobre critérios de avaliação, sobre a necessidade de construir políticas e práticas que levem em conta essa diversidade e que estejam comprometidas com o sucesso, e não com o fracasso escolar (Canen, 2005, p. 18).

[...] Existem preconceitos contra ambos os tipos de avaliação - somativa e diagnóstica - por parte de muitos educadores. No caso da avaliação somativa, muitos a acusam de classificatória e excludente, já que estaria fornecendo um "juízo final" a respeito de 
alunos, atribuindo-lhes o estigma de "incompetentes". No que diz respeito à avaliação diagnóstica ou formativa, muitos temem que leve a uma pouca clareza sobre a qualidade da aprendizagem, pois não forneceria um "conceito", "nota” ou uma apreciação final. Defendemos que ambos os tipos de avaliação são relevantes. Na medida em que a avaliação somativa é feita no contexto de um processo de avaliação contínua, diagnóstica, formativa, que levou em conta momentos e instrumentos plurais de avaliação, ela pode fornecer um grau, conceito, nota ou qualquer outro símbolo, com fundamentação no processo realizado no decorrer do período, diferentemente de uma avaliação somativa que se limite a apenas um instrumento único (Canen, 2005, p. 18-19).

Nessa perspectiva, o trabalho também voltava-se para as tensões entre projetos mais amplos, de caráter nacional e estadual, defendidos no âmbito das políticas públicas em que as escolas estaduais estão imersas e sua ressignificação, no contexto da pluralidade das identidades escolares e de seus atores. Conforme argumentado, tratava-se, nesta abordagem multicultural, de buscar o trabalho com as tensões propriamente ditas, encaradas como possibilidades concretas de se trabalhar o multiculturalismo sem recair em perspectivas centralizadoras, pretensamente universais. Por outro lado, não desejávamos resvalar para uma visão relativista multicultural por nós rejeitada. Algumas ilustrações são fornecidas a seguir, da forma como tais tensões formaram parte da construção discursiva multicultural que buscamos nos temas didáticos, curriculares e pedagógicos com que trabalhamos:

A partir de nossa perspectiva multicultural de compreensão do projeto político-pedagógico, não estamos privilegiando nem uma visão centralizadora, homogeneizadora do processo, nem estamos advogando um relativismo total, defendido por alguns multiculturalistas (que seriam a favor da construção de projetos político-pedagógicos totalmente plurais, sem qualquer esforço de diálogo com um projeto político mais amplo, de caráter nacional, estadual, municipal ou local). Ao contrário, a visão do projeto como uma construção a ser trabalhada nas tensões entre essas esferas pressupõe um diálogo constante entre a pluralidade e as políticas educacionais públicas, fertilizando-se e alterando-se mutuamente, da mesma forma que falamos sobre propostas curriculares e avaliativas, em módulos anteriores (Souza, Bezerra, 2005, p. 17).

Em uma terceira perspectiva, conforme salientado anteriormente, pensar multiculturalmente sobre a formação continuada também significava levar em conta as identidades plurais dos atores envolvidos (no caso, os coordenadores pedagógicos), em termos de seus marcadores identitários singulares de raça, etnia, cultura, visões de mundo e outros. Isso significava, também, visualizar a identidade dos coordenadores pedagógicos como mediadores da construção e reconstrução identitária de docentes, discentes e da própria identidade escolar em que atuam. Tal visão implicava construções discursivas que mobilizassem essas identidades no sentido de trabalhar com a construção e reconstrução identitária de docentes, discentes e da própria instituição escolar.

Para tal, além das tensões multiculturais que impregnavam os conteúdos e temas trabalhados nos módulos, tratava-se de proceder a discursos que interpelassem os coordenadores pedagógicos, que os tratassem não como objeto da formação continuada, mas como sujeitos ativos, participantes, parceiros dessa formação, que constroem e reconstroem suas identidades no processo.

Tais discursos, também, deveriam trazer em seu bojo a mobilização para a ação e não para o consumo do discurso "da academia”, em relação de poder desigual no âmbito da formação continuada. Somente assim poderíamos estar seguros de desenvolver uma ação multiculturalmente orientada, formando coordenadores que fossem pesquisadores em ação, sujeitos autores de seus discursos, como comentamos anteriormente.

A construção discursiva mobilizadora do pensamento e da ação dos coordenadores pedagógicos não foi neutra, como não é neutro nenhum discurso. Ao contrário, foi impregnada de uma intencionalidade transformadora, em termos de trabalho de construção e reconstrução de suas identidades plurais, enquanto mediadores de ações e de construções e reconstruções identitárias na escola. Essa perspectiva foi buscada em um duplo movimento: em 
primeiro lugar, por intermédio da construção dos discursos que a eles se dirigiam. Nesses, interrompíamos a narrativa dos módulos que versava sobre os temas em questão por meio de "choques", obtidos por sentenças que a eles se dirigiam, em uma perspectiva dialógica no texto. Essa técnica já havia sido sugerida por Canen e Oliveira (2002) em práticas didático-pedagógicas multiculturalmente comprometidas, na sala de aula. Esse ponto pode ser melhor compreendido nos exemplos a seguir:

Caro coordenador, este é o momento de traduzir, em uma prática, o que vimos discutindo [...]. Nesta seção, você vai planejar, apresentar e avaliar, em grupo, uma atividade com recursos da Informática. Inicialmente, forme um grupo para elaborar uma atividade que envolva a informática na educação (curso de capacitação de professores, pesquisa, aula, projeto, grupo de discussões, etc.), exponha o que tem em mente e vá anotando em tópicos, juntamente com o que dizem seus parceiros de trabalho [...]. Em seguida a esta atividade, forneceremos um roteiro para que o grupo desenhe, com mais clareza, o que pretende fazer (Repsold, Marinho, 2005, p. 39).

Prezado coordenador: como caracterizaria o seu "olhar" na sua prática cotidiana? Encontra-se próximo ou distante daquele idealizado nesses depoimentos? Lembrese que há um olhar imediato de curto alcance, um olhar que nos faz chegar às pessoas e aos problemas do cotidiano. Mas há outro olhar, mais amplo, que nos faz projetar o futuro, o que desejamos construir a médio e longo prazos. É também um olhar necessário na coordenação pedagógica (Stuhler, Assis, 2005, p. 26).

Em uma segunda perspectiva, a construção discursiva, além do multiculturalismo impregnado nos conteúdos dos módulos, como exemplificado mais acima, buscava também ressignificar suas identidades para além de sujeitos que "sofriam” uma formação continuada, para caminhar no sentido de vê-los igualmente como pesquisadores-em-ação.

Essa estratégia discursiva permitiu que, além das discussões sobre os temas, em uma visão multicultural, fosse requisitada dos coordenadores pedagógicos uma reflexão mobilizadora de ações transformadoras nas escolas em que atuavam, replicando o nosso próprio papel, como professores formadores que estavam atuando como pesquisadores em ação, no âmbito da construção e reconstrução identitária dos coordenadores pedagógicos. Em outras palavras, buscou-se romper com os dualismos eu-outro, sujeito-objeto de ação de formação continuada, e trazer a perspectiva da pesquisa-ação para o espaço das identidades e subjetividades não só de nós, professores formadores tutores, mas para aquele dos próprios coordenadores pedagógicos, em seus contatos, choques e entrechoques culturais com as identidades docentes e discentes nas escolas.

Alguns exemplos contidos nos módulos ilustram essa perspectiva:

A partir das idéias discutidas neste módulo sobre avaliação da aprendizagem, apresentamos o roteiro, a seguir, com questões para serem respondidas por você, a partir de uma análise da realidade de sua escola. Este roteiro servirá como orientador para uma ação, que deve ser realizada nos moldes de uma pesquisaação, buscando promover, transformar ou dinamizar uma avaliação da aprendizagem em uma perspectiva diagnóstica, multicultural e formativa... Os resultados desta intervenção deverão ser trazidos no próximo encontro (Canen, 2005, p. 30).

Agora, vamos trabalhar com uma proposta de ação, na escola. Releia o texto deste módulo e faça o que se pede. Você deverá apresentar, pelo menos, uma das ações a seguir, como trabalho de casa, para efetivar a perspectiva de ação que esperamos desenvolver no curso, como você tem percebido no decorrer dos módulos (Canen et al., 2005, p. 32)

Assim, longe de limitarmos a pesquisa-ação à nossa ação e reflexão, como pesquisadores e professores universitários, ressignificamos esse olhar na formação continuada desenvolvida. A tripla perspectiva pela qual a pesquisa-ação buscou traduzir o multiculturalismo para o âmbito dos discursos construídos sobre temas didático-pedagógico-curriculares buscou contribuir para uma formação multicultural continuada tanto dos atores escolares como universitários envolvidos. Entendemos, como argumentado anteriormente, que o 
multiculturalismo não pode ser defendido como uma narrativa mestra, mas como perspectiva que mobilize as identidades plurais na construção de discursos inovadores, transgressores, transformadores, em prol da construção e reconstrução das identidades abertas à pluralidade e desafiadoras de congelamentos e discriminações.

\section{Conclusões}

O presente artigo partiu da necessidade de se pensar sobre a formação continuada de professores e gestores educacionais, bem como dos pesquisadoresformadores envolvidos nesse tipo de ação, a partir da categoria identidade, central no multiculturalismo. Tal categoria foi entendida de forma mais alargada, de modo a avançarmos em pesquisas no campo do multiculturalismo que não se limitem à categoria identidade em uma visão individualizada ou mesmo coletiva, desprezando a construção identitária da escola, de seus atores e daqueles que participam de processos de formação continuada. A partir dessa perspectiva, analisamos os discursos produzidos nos módulos didático-pedagógico-curriculares construídos para o curso de formação continuada de coordenadores pedagógicos do Rio de Janeiro, desenvolvido em parceria da UFRJ com a SEE-RJ em 2005. Discutimos as formas pelas quais concebemos a construção e reconstrução identitária de coordenadores pedagógicos envolvidos nessa ação política e social, em uma perspectiva multicultural. Nos limites do artigo, focalizamos especificamente as opções de tradução do multiculturalismo na construção dos discursos contidos nos módulos produzidos para o referido curso, deixando para futuros trabalhos a análise dos desdobramentos a partir dessa proposta.

Trabalhar com a pesquisa-ação como caminho multiculturalmente comprometido permitiu levar em conta a especificidade identitária dos atores escolares com que lidávamos e impregnou os discursos que construímos a respeito dos temas didáticos, pedagógicos e curriculares para a formação continuada em tela. Buscamos, conforme discutimos no presente artigo, pensar multiculturalmente sobre a formação continuada em termos de temas que eram tensionados a partir dos próprios desafios entre o universalismo e o particularismo presentes no pensamento multicultural. Ao mesmo tempo, articulávamos essa tensão aos temas específicos, tais como currículo, avaliação, projeto político-pedagógico e outros desenvolvidos. Da mesma forma, tratávamos as identidades plurais dos coordenadores pedagógicos de forma dialógica, encarando-os como interlocutores e atores ativos e culturalmente situados no decorrer de toda a ação.

Conforme temos argumentado, os sentidos do multiculturalismo acima expostos e a visão da escola como organização multicultural podem abrir caminhos para se pensar em respostas que ressignifiquem os discursos que circulam na escola e na universidade. Tal perspectiva pode resultar em encontros e parcerias que produzam práticas de ensino multiculturalmente comprometidas. Futuros trabalhos podem buscar, a partir do exposto, as hibridizações e ressignificações discursivas desenvolvidas pelos sujeitos no âmbito de cursos dessa natureza, de modo a ampliar as discussões sobre a construção e reconstrução das identidades dos atores envolvidos e das instituições nas quais atuam. Dessa forma, tais pesquisas podem continuar contribuindo para trazer as reflexões multiculturais para os espaços do cotidiano escolar e da formação de professores e gestores, reflexões essas cada vez mais necessárias para a formação educacional em um mundo marcado por conflitos culturais e barreiras contra aqueles percebidos como "os outros". 


\section{Referências bibliográficas}

ANDRÉ, M. E. D. A. Etnografia da prática escolar. São Paulo: Cortez, 1995.

ASSIS, M. D. P.; CANEN, A. Identidade negra e espaço educacional: vozes, histórias e contribuições do multiculturalismo. Cadernos de Pesquisa, v. 34, n. 123, p. 709$724,2004$.

BARBIER, R. A pesquisa-ação. Brasília: Liber Livro, 2002. (Série Pesquisa em Educação, v. 3).

CANDAU, V. M.; SACAVINO, S. B.; MARANDINO, M.; MACIEL, A. G. Tecendo a cidadania: oficinas pedagógicas de direitos humanos. Petrópolis: Vozes, 1995.

CANEN, A. Avaliação da Aprendizagem. Rio de Janeiro: Secretaria de Estado de Educação/Universidade Federal do Rio de Janeiro, 2005. (Formação Continuada para Coordenadores Pedagógicos, Programa Sucesso Escolar, Módulo VII).

Institutional Evaluation, Knowledge and Multiculturalism: some ways ahead in Brazilian Higher Education. Current Issues in Comparative Education, Teachers College, Columbia University, v. 6, n. 1, 2004.

CANEN, A. G.; CANEN, A. Organizações multiculturais. Rio de Janeiro: Ciência Moderna, 2005.

CANEN, A.; OLIVEIRA, A. M. A. de. Multiculturalismo e Currículo em Ação: um estudo de caso. Revista Brasileira de Educação, n. 21, p. 61-74, 2002.

CANEN, A.; DE OLIVEIRA, L. F.; ASSIS, M. D. P. de. Currículo: uma questão de cidadania. Rio de Janeiro: Secretaria de Estado de Educação/Universidade Federal do Rio de Janeiro, 2005. (Formação Continuada para Coordenadores Pedagógicos, Programa Sucesso Escolar).

GOMES, N. L.; GONÇALVES E SILVA, P. Experiências étnico-culturais para a formação de professores. Belo Horizonte: Autêntica, 2002.

HALL, S. Da diáspora: identidades e mediações culturais. Belo Horizonte: UFMG, 2003.

KINCHELOE, J. L.; STEINBERG, S. Changing multiculturalism. Buckingham: Open University Press, 1997.

LAVINAS PEREIRA, M. I. Currículo II: traduções para o dia-a-dia da escola. Rio de Janeiro: Secretaria de Estado de Educação/Universidade Federal do Rio de Janeiro, 2005. (Formação Continuada para Coordenadores Pedagógicos, Programa Sucesso Escolar)

REPSOLD, M.; MARINHO, V. do C. Tecnologia educacional. Rio de Janeiro: Secretaria de Estado de Educação/Universidade Federal do Rio de Janeiro, 2005. (Formação Continuada para Coordenadores Pedagógicos, Programa Sucesso Escolar, Módulo VI)

SOUZA, A. E. C. da C.; BEZERRA, M. J. S. Projeto Político-Pedagógico I. Rio de Janeiro: Secretaria de Estado de Educação/Universidade Federal do Rio de Janeiro, 2005. (Formação Continuada para Coordenadores Pedagógicos, Programa Sucesso Escolar, Módulo X)

STUHLER, G. D.; ASSIS, M. D. Relações interpessoais. Rio de Janeiro: Secretaria de Estado de Educação/Universidade Federal do Rio de Janeiro, 2005. (Formação Continuada para Coordenadores Pedagógicos, Programa Sucesso Escolar, Módulo V) 
XAVIER, G. P. DE M. Educação inclusiva. Rio de Janeiro Secretaria de Estado de Educação/Universidade Federal do Rio de Janeiro, 2005. (Formação Continuada para Coordenadores Pedagógicos, Programa Sucesso Escolar, Módulo IV)

Ana Canen, Ph.D em Educação pela University of Glasgow, Escócia, é professora adjunta do Departamento de Fundamentos da Educação da Faculdade de Educação da Universidade Federal do Rio de Janeiro (UFRJ) e pesquisadora do CNPq.

acanen@globo.com

Angela Rocha dos Santos, doutora em Matemática pelo Instituto de Matemática da Universidade Federal do Rio de Janeiro (UFRJ), é professora adjunta desse Instituto e decana do Centro de Ciências Matemáticas e da Natureza (CCMN/UFRJ).

angela@im.ufrj.br

Recebido em 19 de maio de 2006.

Aprovado em 11 de setembro de 2006. 